\title{
Ulcerative colitis in the Jewish population of Southern Israel 1961-1985: epidemiological and clinical study
}

\author{
H S ODES, D FRASER, AND J KRAWIEC
}

From the Gastroenterology Unit, Division of Medicine, and the Epidemiology and Health Services Evaluation Unit, Soroka University Hospital and Faculty of Health Sciences, Ben-Gurion University of the Negev, Beer Sheva, Israel.

SUMmARY The incidence of ulcerative colitis in the Jewish population of Southern Israel has increased in the period $1961-85$ and is presently $5 \cdot 8 / 10^{5} /$ year. The mean annual incidence was significantly higher in European and American born (10.8/10\%/year) than in Asian and African or Israeli born Jews. The disease was significantly more prevalent in women, who developed the illness at a younger age and had a milder course. The age adjusted prevalence rate in each population group was greater than the rates detected by earlier studies in other areas of the country $(\mathrm{p}<0.05)$. The prevalence rate in the total population now approximates the moderate to high prevalence rates of ulcerative colitis found in many other localities. The particularly high rates of ulcerative colitis in the European and American born population in Israel, in Jews residing in Western countries, and in certain non-Jewish populations in Great Britain and Northern Europe may imply the presence of a common aetiological mechanism.

Early investigators ${ }^{2}$ observed that ulcerative colitis was relatively common in Jewish as opposed to other populations. In a subsequent study ${ }^{3}$ of ulcerative colitis from central Israel, however, a lower prevalence rate than expected was reported in the Jewish population of Tel Aviv. A more recent study in Jerusalem, however, detected a higher incidence rate of ulcerative colitis in the Jewish population. ${ }^{+}$We therefore considered it of importance to investigate the epidemiology and clinical features of this disease in the Beer Sheva district of southern Israel, and to compare these data with previously reported studies in Israel and other countries.

\section{Methods}

PATIENTS

A retrospective study of ulcerative colitis over the 25 year period 1961-1985 was carried out in the Beer Sheva district. This area is situated in the Negev in southern Israel and Beer Sheva is the largest city in

Address for correspondence: Dr H S Odes, Division of Gastroenterology, Soroka University Hospital, PO Box 151, Beer Sheva 84101, Israel.

Received for publication 21 May 1987. the region. As ulcerative colitis has been detected in only two members of the local Arab (Bedouin) community, the study was confined to the Jewish population. This population grew by natural increase and immigration from 78900 in 1961 to 232295 in 1985. Thirteen per cent of the population is rural. Almost all citizens in the district are enrolled in various prepaid health insurance plans and the Soroka University Hospital in Beer Sheva is the only hospital in the area. The records were reviewed of all cases of ulcerative colitis seen at the hospital and in the various community clinics operating in association with the hospital. In fact, most patients with ulcerative colitis are followed in a special Inflammatory Bowel Diseases Clinic operated in the Gastroenterology Unit (established 1963). In addition, physicians, surgeons, paediatricians and family practitioners assisted in locating 20 patients treated elsewhere. A detailed computerised questionnaire was completed for each case. Only subjects permanently residing in the area were included in the incidence data, and only subjects actually living in the district on the date of 31 December 1985, were used in the calculation of the point prevalence rate. The age distribution of the population, and of the subgroups by place of birth (Europe-America $16 \%$, Asia-Africa $26 \%$ or Israel $58 \%$ ), were obtained from census enumeration (1961, 
$1972,1983)$ and midcensus estimates $(1967,1977)$ of the Central Bureau of Statistics, Jeruselem.

DISEASE DEFINITION ${ }^{3+}$

Ulcerative colitis was diagnosed by a typical history of relapsing or continuous disease ('acute' disease was excluded) with radiological, rectocolonoscopic and histological features characteristic of the disease. All patients had negative stool cultures for pathogenic organisms. Amoebic colitis was excluded. A particular effort was made to exclude cases of Crohn's colitis (three patients) and undefined forms of colitis (10 patients).

Definitions of the anatomical distribution of disease were based on radiological and more usually on colonoscopic biopsy findings. Disease of the rectum or rectosigmoid was called distal disease. When the descending \pm transverse colon was involved the disease extent was defined as extensive. When the entire colon was involved the disease was designated as total.

The course of disease referred to the patients' pattern of symptomatology. Relapsing disease implied the occurrence of symptom free period(s) of at least one month's duration where steroid treatment ceased. Continuous disease occurred when there were no symptom free periods.

The current status of disease referred to the most severe symptoms of the patient during 1985. Thus mild status implied four or fewer motions per 24 hour period, with very little or no macroscopic bleeding and no constitutional features. Remission implied the presence of normal bowel function. Severe status implied six or more stools per 24 hour period with blood, fever, tachycardia, and anaemia. Moderate status was intermediate between mild and severe. For the computation of results, mild status and remission were grouped together and moderate and severe status formed a second group.

Complications were called local when the colon and anus were involved and remote when extracolonic organs were implicated.

STATISTICAL ANALYSIS

The age specific prevalence rates were based on the Beer Sheva region data of the 1983 Israeli census. Age adjusted rates were calculated by the direct method with the use of Segi's world standard population. ${ }^{5}$ The $95 \%$ confidence interval for the adjusted rates assumed that the number of observed cases in the numerator was a Poisson variate and that the population denominator was not subject to sampling variation." Differences between the age adjusted prevalence rates of the population subgroups in Tel Aviv and Jerusalem (as calculated by us from the original data given in those reports ${ }^{3+}$ ), and the present results for Beer Sheva, were computed according to Bailar and Ederer.' Chi square statistic was used to test the statistical significance of the distribution of categorical variables and the student's $t$ test was used to test differences between the means of age of onset of various patient groups. Differences were considered significant when $\mathrm{p}<0 \cdot(05$.

\section{Results}

One hundred and sixty nine incident cases of ulcerative colitis were seen over the period 1961-85. Two patients died during the study period and three left the area. Thus there were 164 cases resident in the district on the prevalence date. The ratio of men to women was ().76. Women outnumbered men in all age groups up to age 54 years.

All the subjects developed the illness while residing in the Beer Sheva area, apart from seven EuropeAmerica born patients (two men, five women) who arrived with existing colitis. Because these constituted a small portion of this group's cases (53) and varied in age from 25 to 65 years, no separate analysis of this immigrant group was required in the calculation of incidence.

PREVALENCE

The point prevalence rate of ulcerative colitis in the total population was $70 \cdot 6 / 10^{5}$ on 31 December 1985 ; in men the rate was $60 \cdot 3 / 10^{5}$ and in women $81 \cdot 2 / 10^{5}$ $(<0 \cdot 01)$. The age specific prevalence rates in the population are shown in Table 1 . In the total population, as in the women, the highest age specific prevalence rates were in the ages $35-54$ years. In men, however, the age specific prevalence rates were highest above age 54 years.

The age adjusted prevalence rates were as follows: total population $78 \cdot 3 / 10^{5}$, men $68 \cdot 7 / 10^{5}$ and women

Table 1 Agespecific prevalence rate of ulcerative colitis in the Beer Sheva district on 31 December 1985

\begin{tabular}{crccr}
\hline \multicolumn{5}{c}{ Age specific prevalence rate/105 } \\
Age group & $n$ & All patients & \multicolumn{1}{c}{ Men } & \multicolumn{1}{l}{ Women } \\
\hline $0-14$ & 1 & $1(0-7)$ & - & $3(0-15)$ \\
$15-24$ & 21 & $48(28-77)$ & $40(18-75)$ & $57(29-99)$ \\
$25-34$ & 41 & $103(74-140)$ & $93(56-146)$ & $113(71-170)$ \\
$35-44$ & 38 & $152(108-207)$ & $113(61-190)$ & $140(90-209)$ \\
$45-54$ & 31 & $165(112-236)$ & $96(43-182)$ & $235(147-355)$ \\
$55-64$ & 16 & $121(69-196)$ & $155(75-286)$ & $88(32-193)$ \\
$65-74$ & 11 & $134(67-239)$ & $182(73-375)$ & $91(25-234)$ \\
$75+$ & 5 & $129(42-301)$ & $166(34-486)$ & $97(12-349)$ \\
All ages & 164 & $71(60-83)$ & $60+(47-77)$ & $81+(66-101)$ \\
\end{tabular}

* $95 \%$ Confidence intervals; $†$ Significant difference between males and females $\mathrm{p}<0 \cdot(01$. 
Table 2 Mean annual age adjusted ${ }^{*}$ incidence rate of ulcerative colitis in the Beer Sheva district by place of birth and time

\begin{tabular}{|c|c|c|c|c|}
\hline \multirow[b]{2}{*}{ Period } & \multicolumn{4}{|c|}{ Age adjusted incidence rate/l(15/year $\left(95 \%\left(\mathrm{Cl}^{+}\right)\right.$} \\
\hline & All patients & Europe-America born & Asia-Africa horn & Israel born \\
\hline $1961-75$ & $2 \cdot 0(1 \cdot 4-2 \cdot 7)$ & $5 \cdot 6(3 \cdot 4-8 \cdot 6)$ & $(0.9 \ddagger(0 \cdot 5-1 \cdot 6)$ & $3 \cdot 1 \ddagger(1 \cdot 4-5 \cdot 7)$ \\
\hline $1976-85$ & $5 \cdot 8 \$(4 \cdot 8-7 \cdot(0)$ & $10 \cdot 8 \|(7 \cdot 5-15 \cdot(1)$ & $5 \cdot 1 \div \$(3 \cdot 6-6 \cdot 9)$ & $4 \cdot 1 \ddagger(3 \cdot 0-5 \cdot 4)$ \\
\hline
\end{tabular}

* Age adjusted to world standard population; $\quad+95 \%$ confidence intervals; $\doteqdot$ Significantly different from equivalent period EuropeAmerica born rate $\mathrm{p}<0 .(0)$ : \$Significantly different from 1961-75 rate. $\mathrm{p}<0.01$;: || Significantly different from 1961-75 rate, $\mathrm{p}<0.05$.

$88 \cdot 4 / 10^{5}$. The male and female rates were significantly different $(\mathrm{p}<0) \cdot 05)$.

\section{INCIDENCE}

The mean annual age adjusted incidence rates for the total population and the three ethnic subgroups of the population are recorded in Table 2 . The incidence rates for 1976-85 were higher than in 1961-75 in all the groups. The incidence rate in the Europe-America born population was greater than the rates in the other population groups in both time periods, being twice as high in the period 1976-85. In the last decade of the study period, the mean annual incidence rate in the total population was $5 \cdot 8 / 10 \%$ year.

\section{AGE AT ONSET}

The differences in the age specific prevalence rates in the two sexes were further clarified by the graphical plot for men and women of the cumulative incidence per cent for ulcerative colitis by age at onset of illness (Fig. 1). This shows that women developed the disease at an earlier age $(p<0 \cdot 05)$ than the men in whom incident cases continued to appear in the older ages.

The mean age at onset of ulcerative colitis over several calendar periods was fairly steady in men and women (Fig. 2). As anticipated, the mean age

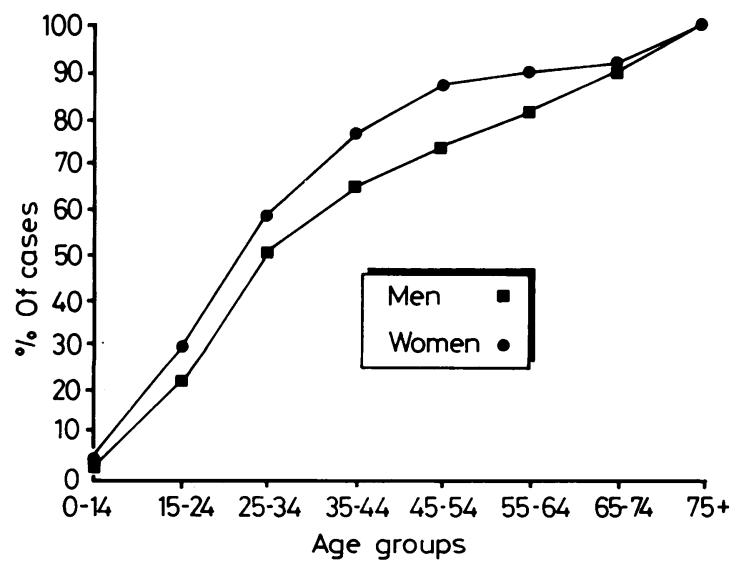

Fig. 1 Cumulative incidence of ulcerative colitis in the Beer Sheva district by sex and age (years) at onset of illness. at onset was lower in the women, although this difference became less in the last decade when some overlap of mean ages at onset occurred. Overall the mean age of onset of men ( \pm standard deviation) was $36 \cdot 1( \pm 16 \cdot 0)$ years which was significantly higher $(p<0 \cdot 05)$ than that of the female patients, $31 \cdot 2$ $( \pm 11 \cdot 5)$ years.

CLINICAL ASPECTS

In the total patient group, mild disease or remission status was documented in $62.6 \%$ of cases and $37.4 \%$ had moderate or severe illness. In $86.4 \%$ of cases the illness was relapsing and in $13.6 \%$ continuous. Distal colitis was present in $59.8 \%$ and extensive or total colitis in $40 \cdot 2 \%$. Complications were documented in $16.9 \%$ of our patients. For local complications the frequency was $10 \cdot 6 \%$ and for remote complications $9 \cdot 4 \%$; each of these percentages includes $3 \cdot 1 \%$ of patients with both local and remote complications. In patients with distal colitis, complications occurred in $11.4 \%$ of cases, compared with $25.9 \%$ in extensive and total colitis $(\mathrm{p}<0 \cdot 05)$.

In the female patients (Table 3 ), mild/remission status occurred in $71 \cdot 1 \%$ as opposed to $50.8 \%$ in men $(p<0 \cdot(01)$. No significant differences between the sexes occurred in respect of anatomical distribution of colitis (distal in men $57.5 \%$, women $61.5 \%$ ) and course (relapsing in men $82.1 \%$, females $89.5 \%$ ).

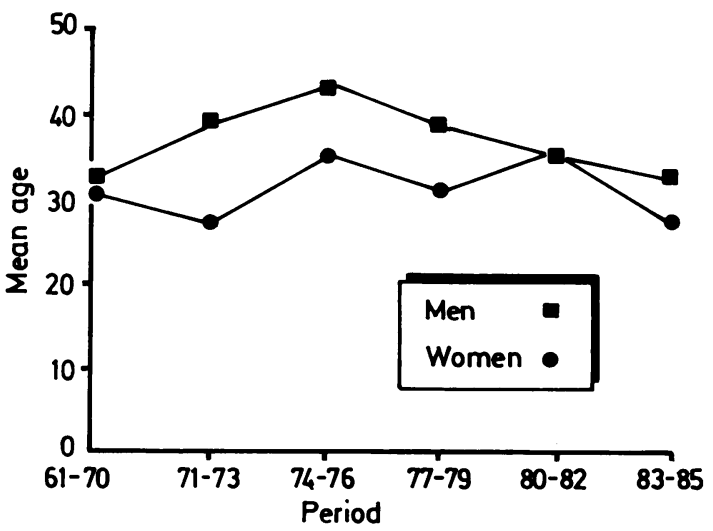

Fig. 2 Mean age (years) at onset of ulcerative colitis in the Beer Sheva district in men and women, 1961-85. 
Table 3 Current status of ulcerative colitis patients by sex and rate of complications

\begin{tabular}{|c|c|c|c|c|}
\hline \multirow[b]{2}{*}{$\begin{array}{l}\text { Current } \\
\text { Status }\end{array}$} & \multicolumn{2}{|c|}{ Sex } & \multicolumn{2}{|c|}{ Complication Rate } \\
\hline & $\begin{array}{l}\text { Male } \\
\%\end{array}$ & $\begin{array}{l}\text { Female } \\
\%\end{array}$ & $\begin{array}{l}\text { Local } \\
\%\end{array}$ & $\begin{array}{l}\text { Remote } \\
\%\end{array}$ \\
\hline Mild/remission & $50 \cdot 8$ & $71 \cdot 1$ & $5 \cdot 5$ & $8 \cdot 8$ \\
\hline Moderate/severe & $49 \cdot 2$ & $28 \cdot 9$ & $20 \cdot 8$ & 13.2 \\
\hline pvalue & \multicolumn{2}{|c|}{$\begin{array}{c}49.2 \\
<(0.01\end{array}$} & $<0 \cdot(0) 1$ & NS \\
\hline
\end{tabular}

Moderate and severe ulcerative colitis was associated with a significantly higher rate of local complications.

The frequency of distal disease did not vary with age at onset and population group. The current status did not vary with these factors nor with the complication rate.

The anatomical extent, current status and clinical course were analysed for the time periods 1961-75 and 1976-85. While the proportion of patients with proctitis increased from $53 \%$ to $62 \%$ and those with remission or mild disease from $54 \%$ to $66 \%$, these differences were not statistically significant. The proportion of cases with continuous rather than relapsing colitis rose from $3 \%$ to $17 \%$ in these time periods $(p<0 \cdot 05)$. The rise in the incidence rate of ulcerative colitis in the population could not be explained as the result of the inclusion of new, mild cases of the disease.

Four patients were treated surgically: one for toxic megacolon, one for colonic carcinoma and two for non-responsive disease. Two patients died of their colitis in addition to the patient with carcinoma. Eighty per cent of the patients never required hospitalisation.

The delay between onset of symptoms and date of diagnosis of ulcerative colitis was greater than one year in $8 \%$ of patients and was found to be associated with the following: distal colitis, mild or remission status, female sex, Israel born population group, younger age at onset and low rate of complications. It therefore appeared that the milder cases of colitis were those in whom a longer time lapsed between onset of symptoms and diagnosis.

\section{COMPARISON WITH PREVIOUS STUDIES FROM} IS RA E L

While the incidence and prevalence of ulcerative colitis has varied in different countries, the disease was regularly found to be very common in Jewish populations outside of Israel (Table 4). A relatively high prevalence rate was detected in Beer Sheva in

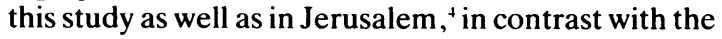
lower rate reported in the Tel Aviv region. ${ }^{3}$ A comparison of the age adjusted prevalence rates of ulcerative colitis in the three localities studied to date in Israel revealed a significantly higher rate of prevalence of the illness in Beer Sheva than documented earlier in Tel Aviv and Jerusalem (Table 5).

\section{Discussion}

A considerable increase in the mean annual incidence rate of ulcerative colitis in the Beer Sheva region of Israel has been observed over the time span 1961-85. This increase was detected in the total population and in the Europe-America and Asia-Africa born populations, while the Israel born population showed little change (Table 2). In considering whether these differences are real or not, factors to be considered include: the availability of medical facilities, the awareness among physicians of the illness, and the inclusion of mild forms of disease such as proctitis. As the Asia-Africa born segment of the population immigrated to Israel largely from 1961 to 1970 , it is very likely that the rarity of the diagnosis in that population group in the early period of the study reflects a lack of medical facilities. This consideration would not apply to populations that were established in this country. A heightened awareness of the illness was unlikely to cause over diagnosis, because the criteria for selection of cases were very strict. Furthermore, the proportion of cases of proctitis did not change significantly during the study period, while the percentage of patients with chronic continuous colitis actually increased significantly from 1961 to 1985 .

The first epidemiological study of ulcerative colitis from this country was that of Gilat et al. ${ }^{3}$ The suprising finding in that study was the low prevalence rate of ulcerative colitis in Tel Aviv, 37/10' population in 1970. That the prevalence of ulcerative colitis in Beer Sheva at a corresponding time period was similar, was also unexpected: because the proportion (but not the age distribution) of Europe-America born Jews was different in Tel Aviv (38\%) and Beer Sheva $(16 \%)$, the prevalence should have been higher in Tel Aviv. A more recent study from Jerusalem (Europe-America born Jews, 21\%) reported a rate of $57 / 10^{5}$ population in $1978 .{ }^{4}$ In the latest study, from Beer Sheva, the rate was higher still. It is possible that earlier investigators underestimated the number of cases of colitis. We were impressed nevertheless by the progressive increase of the age adjusted prevalence rates of the disease in all populations with time, when the three areas of Israel were compared. Despite the notion that ulcerative colitis is a disease with a stable incidence rate, certain recent studies have noted a rising incidence of the disease. . $^{-11}$

By comparison, Crohn's disease appears to occur with equal frequency in Beer Sheva, with a prevalence 
Table 4 Occurrence of ulcerative colitis

\begin{tabular}{|c|c|c|c|c|}
\hline Locality & Period & Population & Incidence (cases $/ 10^{5}$ population) & Prevalence (cases $/ 10^{5}$ population) \\
\hline \multicolumn{5}{|l|}{ USA } \\
\hline Rochester $^{19}$ & 1964 & General & $7 \cdot 2$ & $87 \cdot 6$ \\
\hline Baltimore $^{15}$ & $1960-63$ & Jewish & $13 \cdot 1$ & $42 \cdot 0$ \\
\hline Baltimore $^{15}$ & $1960-63$ & General & $4 \cdot 6$ & \\
\hline Baltimore $^{21}$ & $1977-79$ & Jewish & $9 \cdot 8$ & \\
\hline Baltimore $^{211}$ & $1977-79$ & General & $5 \cdot 8$ & \\
\hline \multicolumn{5}{|l|}{ South Africa } \\
\hline Cape Town ${ }^{16}$ & $1980-84$ & Jewish & $17 \cdot 0$ & \\
\hline Cape Town ${ }^{16}$ & $1980-84$ & General & $5 \cdot 0$ & \\
\hline Johannesburg ${ }^{17}$ & 1978 & Jewish & & $184 \cdot 0$ \\
\hline \multicolumn{5}{|l|}{ Great Britain } \\
\hline Oxford $^{18}$ & $1951-60$ & General & $6 \cdot 5$ & $79 \cdot 9$ \\
\hline Cardiff $^{21}$ & $1968-77$ & General & $7 \cdot 2$ & \\
\hline Aberdeen ${ }^{8}$ & $1967-76$ & General & $11 \cdot 3$ & \\
\hline North Tees ${ }^{111}$ & $1971-77$ & General & $15 \cdot 1$ & $99 \cdot 0$ \\
\hline \multicolumn{5}{|l|}{ Scandinavia } \\
\hline Finland $^{22}$ & 1967 & General & $4 \cdot 8$ & \\
\hline Bergen $^{23}$ & $1976-80$ & General & $10 \cdot 0$ & \\
\hline Stockholm $^{24}$ & $1970-79$ & General & $4 \cdot 5$ & \\
\hline Copenhagen $^{25}$ & $1962-78$ & General & $8 \cdot 1$ & $117 \cdot 0$ \\
\hline Faroe Islands ${ }^{9}$ & 1983 & General & & $157 \cdot 3$ \\
\hline \multicolumn{5}{|l|}{ Arabia } \\
\hline Kuwait $^{26}$ & $1977-82$ & Arab $94 \%$ : Non-Arab 6\% & $2 \cdot 3$ & \\
\hline \multicolumn{5}{|l|}{ Israel } \\
\hline Tel Aviv ${ }^{3}$ & $1961-70$ & Total Jewish pop. & $3 \cdot 7$ & $37 \cdot 4$ \\
\hline Tel Aviv ${ }^{3}$ & $1961-70$ & Europe-America born & & $52 \cdot 2$ \\
\hline Jerusalem $^{4}$ & $1973-78$ & Total Jewish pop. & $6 \cdot 3$ & $56 \cdot 7$ \\
\hline Jerusalem $^{4}$ & $1973-78$ & Europe-America born & $11 \cdot 7$ & $119 \cdot 1$ \\
\hline Beer Sheva & $1976-85$ & Total Jewish pop. & $5 \cdot 8$ & $70 \cdot 6$ \\
\hline Beer Sheva & $1976-85$ & Europe-America born & $10 \cdot 8$ & $138 \cdot 7$ \\
\hline
\end{tabular}

Table 5 Age adjusted * prevalance rate of ulcerative colitis in three localities of Israel by place of birth

\begin{tabular}{lcccc}
\hline Locality & \multicolumn{2}{c}{ Age-adjusted prevalence ratel10 } \\
& Year & Europe-America born & Asia-Africa born & Israel born \\
\hline Tel Aviv $^{3}$ & 1970 & $31 \cdot 3(24-39) \ddagger \S$ & $17 \cdot 2(10-27) \ddagger$ & $23 \cdot 6(16-34) \ddagger \S$ \\
Jerusalem $^{4}$ & 1978 & $94 \cdot 1(73-119) \|$ & $24 \cdot 0(15-37) \ddagger$ & $70 \cdot 2(54-91)$ \\
Beer Sheva & 1985 & $129 \cdot 3(99-168)$ & $64 \cdot 1(49-83)$ & $97 \cdot 6(72-129)$ \\
\hline
\end{tabular}

* Age adjusted to world standard population; † $95 \%$ confidence intervals; $\ddagger$ Significantly different from corresponding Beer Sheva rate, $\mathrm{p}<0.01 ; \S$ Significantly different from corresponding Jerusalem rate, $\mathrm{p}<0.01 ; \|$ Significantly different from corresponding Beer Sheva rate, $\mathrm{p}<0.05$.

rate of $14.0 / 10^{5}$ population in $1980 . "$ and in Tel Aviv, $12 \cdot 3 / 10^{5}$ population in $1976 .^{12}$ This low frequency of Crohn's disease is sharply contrasted with the five fold greater prevalence of ulcerative colitis in Beer Sheva.

The lower frequency of ulcerative colitis in the Asia-Africa born and Israel born population, as opposed to the Europe-America born population, was noted in previous studies in Israel. ${ }^{3+13}$ The finding of similar rates in the Israel born and AsiaAfrica born populations was unexpected and this presumably has aetiological implications, as a large part of the Israel born population is the offspring of immigrants from Europe and America.

The epidemiology of ulcerative colitis was reviewed recently in detail ${ }^{14}$ and the higher incidence of the illness in Western countries was emphasised. It has long been known that the Jewish populations of several Western countries are at much greater risk to develop ulcerative colitis. ${ }^{1+18}$ It now appears that the risk in Europe-America born Jews living in Israel, in contrast with previous observations, ${ }^{3}$ is as great as that of Jews of European and American extraction in other countries. In this context it is important to note 
that certain areas of Great Britain ${ }^{x 111}$ and Europe ${ }^{433.25}$ exhibit a very high incidence of ulcerative colitis and it is tempting to speculate that these populations share with the Europe-America born Jews a genetic and/or environmental factor, or combination of factors, causing a heightened susceptibility to the disease.

The nature of any causative agent(s) is quite unknown at present, ${ }^{1+211}$ but several possibilities do arise. In regard to genetic influences, however, a recent study showed that the risk in family members was no greater for Jewish than Catholic and Protestant probands. ${ }^{27}$ While Africa-Asia born Jews have a higher incidence of lactose intolerance and of glucose-6-phosphatase deficiency, and while Jews with European and American origin had a greater frequency of HLA-BW 35 than controls, ${ }^{28}$ there is no firm evidence of any genetic predisposition among Jews. Social, educational, religious and marital factors did not discriminate between Jews and the general USA population. ${ }^{20} \mathrm{~A}$ dietary factor might be important, given the high meat and fat diet of Jews born in Europe and America and the high fibre diet of Israel and Asia-Africa born Jews, but this requires further investigation. Lack of exposure to sunlight might be a contributory cause for certain European populations at higher risk, and the Jews originating in Northern Europe, but would not explain the higher rate of colitis in Jews in the USA. These and other factors merit investigation in case control studies, but it is possibly more urgent to carry out basic, descriptive epidemiological studies in various Jewish and non-Jewish populations in order to define the exact risk to each group. ${ }^{21}$

The paucity of cases in our local Arab population was not unexpected. While the small number of patients makes epidemiological evaluation meaningless at the present, it does suggest that ulcerative colitis is quite uncommon in this group, as the medical facilities for the Arabs are the same as for the rest of the populations. The local Arab population thus expresses the same rarity of this disease as was shown in the population of Kuwait. ${ }^{26}$

The present study has also emphasised a number of important clinical aspects of ulcerative colitis in the Beer Sheva population. Ulcerative colitis is a relatively mild disease in this region. The low hospitalization, surgical, and death rates in this study support this conclusion. Sixty per cent of patients had distal colitis, an important factor favouring a milder form of illness, and in fact these cases had a low complication rate. The milder nature of inflammatory bowel disease in Israel was previously reported for ulcerative colitis ${ }^{3}$ and for Crohn's disease. ${ }^{112}$

Ulcerative colitis is usually more common in women. ${ }^{21}$ In Beer Sheva, too, the disease was more frequently diagnosed in women, who also showed a number of other features. The disease was milder in women, with a high proportion of cases of distal colitis, and appeared at a younger age than in the men. Indeed, only the male patients showed a secondary peak of incidence in the older age groups.

Ulcerative colitis has increased in incidence in the Jewish population of Southern Israel. It is suggested here that epidemiological and other studies be made in other Jewish communities and in European populations to determine if a common aetiologic agent may be uncovered.

The authors would like to thank Professor Jon I Isenberg for his valuable comments and advice.

\section{References}

1 Acheson ED. The distribution of ulcerative colitis and regional enteritis in United States veterans with particular reference to the Jewish religion. Gut 1960; 1: 291-3.

2 Weiner HA, Lewis CM. Some notes on the epidemiology of nonspecific ulcerative colitis. An apparent increase in incidence in Jews. Am J Dig Dis 1960; 5: 406-18.

3 Gilat T, Ribak J, Benaroya Y, Zemishlany Z, Weissman I. Ulcerative colitis in the Jewish population of Tel AvivYafo. 1. Epidemiology. Gastroenterology 1974; 66: $335-42$.

4 Jacobsohn WZ, Levine Y. Incidence and prevalance of ulcerative colitis in the Jewish population of Jerusalem. Isr J Med Sci 1986; 22: 559-63.

5 Waterhouse J, Muir C, Correa P, Powell J. Cancer incidence in five continents. Vol. III. Lyons IARC Sci Pub 1976, 15: 228-32.

6 Haenszel W, Loveland DB, Sirkin MG. Lung cancer mortality as related to residence and smoking histories in white males. J Natl Cancer Inst 1962; 28: 947-1001.

7 Bailar JC, Ederer F. Significance factor for the ratio of a Poisson variable to its expectation. Biometrics 1964; 20: 639-43.

8 Sinclair TS, Brunt PW, Mowat NAG. Nonspecific proctocolitis in Northeastern Scotland: a community study. Gastroenterology 1983; 85: 1-11.

9 Berner J, Kiaer T. Ulcerative colitis and Crohn's disease on the Faroe Islands 1964-83. Scand J Gastroenterol 1986; 21: 188-92.

10 Devlin HB, Datta D, Dellipiani AW. The incidence and prevalence of inflammatory bowel disease in North Tees Health District. World J Surg 1980; 4: 183-93.

11 Krawiec J, Odes HS, Lasry Y, Krugliak P, Weitzman S. Aspects of the epidemiology of Crohn's disease in the Jewish population in Beer Sheva, Israel. Isr J Med Sci 1984; 20: 16-21.

12 Rozen P. Zonis J, Yekutiel P, Gilat T. Crohn's disease in the Jewish population of Tel Aviv-Yafo: epidemiological and clinical aspects. Gastroenterology 1979; 76: 25-30.

13 Birnbaum D, Groen JJ, Kallner G. Ulcerative colitis among the ethnic groups in Israel. Arch Intern Med 1960: 105: 843-8. 
14 Mayberry JF. Some aspects of the epidemiology of ulcerative colitis. Gut 1985; 26: $968-74$.

15 Monk M. Mendeloff AI, Siegel CI, Lilienfield A. An epidemiological study of ulcerative colitis and regional enteritis among adults in Baltimore. 1: Hospital incidence and prevalence, 1960-63. Gastroenterology 1967; 53: 198-210.

16 Wright JP, Froggatt J, O'Keefe EA, et al. The epidemiology of inflammatory bowel disease in Cape Town 1980-1984. S Afr Med J 1986; 70: 10-15.

17 Segal I, Serebro H, Kavin H. High prevalence of ulcerative colitis in Jews in Johannesburg. South Africa [Abstract]. Gastroenterology 1984; 86: 1242.

18 Evans JG, Acheson ED. An epidemiological study of ulcerative colitis and regional enteritis in the Oxford area. Gut 1965; 6:311-24.

19 Sedlack RE, Nobrega FT, Kurland LT, Sauer WG. Inflammatory colon disease in Rochester, Minnesota, 1935-64. Gastroenterology 1972; 62: 935-41.

20) Calkins BM. Mendeloff AI. Epidemiology of inflammatory bowel disease. Epidemiol Rev 1986; 8: 60-91.

21 Morris T, Rhodes J. Incidence if ulcerative colitis in the Cardiff region 1968-1977. Gut 1984; 25: 846-8.

22 Linden G. Moller C. Ulcerative colitis in Finland: II.
One-year incidence in all hospitals. Dis Colon Rectum 1971; 14: 264-6.

23 Skarstein A. Arnesjo B, Burhol P, et al. The incidence of ulcerative colitis and Crohn's disease in an urban population [Absract]. Scand J Gastroenterol 1982; 17: suppl 78: 349.

24 Nordenvall B. Brostrom O, Berglund M, et al. Incidence of ulcerative colitis in Stockholm county 1955-1979. Scand J Gastroenterol 1985; 20: 783-90.

25 Binder V, Both $\mathrm{H}$, Hanson PK. Hendriksen C, Kreiner $\mathrm{S}$, Torp-Pedersen $\mathrm{K}$. Incidence and prevalence of ulcerative colitis and Crohn's disease in the County of Copenhagen, 1968 to 1978. Gastroenterology 1982; 83: $563-8$.

26 Al-Nakib B, Radhakrishnan S, Jacob GS, AI-Lidawi H, AI-Ruwaih A. Inflammatory bowel disease in Kuwait. Am J Gastroenterol 1984; 79: 191-4.

27 Lashner BA, Evans AA, Kirsner JB, Hanauer SB. Prevalence and incidence of inflammatory bowel disease in family members. Gastroenterology 1986; 91 : $1396-400$.

28 Delpre G, Kadish U, Gazit E, Joshua H, Zamir R. HLA antigens in ulcerative colitis and Crohn's disease in Israel. Gastroenterology 1980; 78: 1452-7. 